\title{
Acetaldehyde as an Intermediate in the Electroreduction of Carbon Monoxide to Ethanol on Oxide-Derived Copper
}

Bertheussen, Erlend; Verdaguer Casadevall, Arnau; Ravasio, Davide; H. Montoya, Joseph; Trimarco, Daniel Bøndergaard; Roy, Claudie; Meier, Sebastian; Wendland, Jürgen; Nørskov, Jens K.; E. L. Stephens, Ifan

Total number of authors:

11

Published in:

Angewandte Chemie International Edition

Link to article, DOI:

10.1002/anie.201508851

Publication date:

2016

Document Version

Publisher's PDF, also known as Version of record

Link back to DTU Orbit

Citation (APA):

Bertheussen, E., Verdaguer Casadevall, A., Ravasio, D., H. Montoya, J., Trimarco, D. B., Roy, C., Meier, S. Wendland, J., Nørskov, J. K., E. L. Stephens, I., \& Chorkendorff, I. (2016). Acetaldehyde as an Intermediate in the Electroreduction of Carbon Monoxide to Ethanol on Oxide-Derived Copper. Angewandte Chemie International Edition, 55(4), 1450-1454. https://doi.org/10.1002/anie.201508851

- You may freely distribute the URL identifying the publication in the public portal 


\title{
Acetaldehyde as an Intermediate in the Electroreduction of Carbon Monoxide to Ethanol on Oxide-Derived Copper
}

\author{
Erlend Bertheussen, Arnau Verdaguer-Casadevall, Davide Ravasio, Joseph H. Montoya, \\ Daniel B. Trimarco, Claudie Roy, Sebastian Meier, Jürgen Wendland, Jens K. Nørskov, \\ Ifan E. L. Stephens, * and Ib Chorkendorff*
}

\begin{abstract}
Oxide-derived copper (OD-Cu) electrodes exhibit unprecedented $\mathrm{CO}$ reduction performance towards liquid fuels, producing ethanol and acetate with $>50 \%$ Faradaic efficiency at $-0.3 \mathrm{~V}$ (vs. RHE). By using static headspace-gas chromatography for liquid phase analysis, we identify acetaldehyde as a minor product and key intermediate in the electroreduction of $\mathrm{CO}$ to ethanol on $\mathrm{OD}-\mathrm{Cu}$ electrodes. Acetaldehyde is produced with a Faradaic efficiency of $\approx 5 \%$ at $-0.33 \mathrm{~V}$ (vs. RHE). We show that acetaldehyde forms at low steady-state concentrations, and that free acetaldehyde is difficult to detect in alkaline solutions using NMR spectroscopy, requiring alternative methods for detection and quantification. Our results represent an important step towards understanding the $\mathrm{CO}$ reduction mechanism on $\mathrm{OD}-\mathrm{Cu}$ electrodes.
\end{abstract}

U tilization of $\mathrm{CO}_{2}$ as a feedstock for producing fuels and commodity chemicals is a highly promising technology for reducing the anthropogenic carbon footprint. Capture of $\mathrm{CO}_{2}$ from point sources or ambient air, followed by reduction, gives an opportunity to close the carbon cycle. ${ }^{[1]}$ Electrochemical technology provides a means of achieving this, as electrochemical devices can operate at ambient conditions, with minimal capital investment, and with fast start-stop cycles enabling coupling to intermittent energy sources. To date, implementation of this technology is hindered by a lack of electrocatalysts capable of converting $\mathrm{CO}_{2}$ into energy-rich products in an efficient and selective manner. Copper is the only pure metal that is active for $\mathrm{CO}_{2}$ reduction towards hydrocarbons and alcohols. ${ }^{[2]}$ However, high overpotentials are needed and a variety of products are formed. Measurements on planar extended surfaces of $\mathrm{Cu}$ electrodes showed that potentials of $-1 \mathrm{~V}$ (vs. RHE), or overpotentials, $\eta>$ $\approx 1.0 \mathrm{~V}$, are needed to produce significant amounts of $\mathrm{C} 2$ products, that is, above $5 \%$ Faradaic efficiency with a current density of $1 \mathrm{~mA} \mathrm{~cm}^{-2}$ or higher. ${ }^{[2-6]}$

A viable route forward is to split the reaction into two sequences; reducing $\mathrm{CO}_{2}$ to $\mathrm{CO}$ at first, and then reducing $\mathrm{CO}$ to the desired product in a second step. Since $\mathrm{CO}$ is a key intermediate in the reduction of $\mathrm{CO}_{2}$ to alcohols and hydrocarbons, $\mathrm{CO}$ reduction can be used as a proxy for understanding trends in $\mathrm{CO}_{2}$ reduction. ${ }^{[2,4]}$ Several catalysts have been reported to reduce $\mathrm{CO}_{2}$ to $\mathrm{CO}$ efficiently and selectively, ${ }^{[7-11]}$ but the second step remains a challenge owing to multi-electron transfer involving several reaction intermediates. $^{[12]}$ This calls for development of new catalysts with improved energy efficiency and selectivity for $\mathrm{CO}$ reduction towards valuable compounds. Kanan and co-workers recently achieved a breakthrough in this area; they showed that oxidation and subsequent reduction of polycrystalline copper yields a high surface area metallic copper electrode with unprecedented $\mathrm{CO}$ electroreduction performance. ${ }^{[13,14]}$ Oxide-derived copper (OD-Cu) has a Faradaic efficiency towards ethanol as high as $43 \%$ at $-0.3 \mathrm{~V}, \eta \approx 500 \mathrm{mV}\left(\mathrm{U}_{\mathrm{CO} /}^{0}\right.$ $\mathrm{CH}_{3} \mathrm{CH} 2 \mathrm{OH}=0.18 \mathrm{~V}$ ), and a total Faradaic efficiency towards CO reduction products of $57 \%$, with a total geometric current density of $\approx 0.3 \mathrm{~mA} \mathrm{~cm}^{-2}$.

The underlying reasons for the high performance of OD$\mathrm{Cu}$ electrodes remain unknown. Our own temperature programmed desorption (TPD) experiments show that the activity correlates with the presence of strong binding sites, which in turn correlates with the presence of grain boundaries. ${ }^{[15]}$ Importantly, the mechanism for ethanol production
[*] E. Bertheussen, Dr. A. Verdaguer-Casadevall, D. B. Trimarco, C. Roy, Prof. Dr. I. E. L. Stephens, Prof. Dr. I. Chorkendorff

Department of Physics, Technical University of Denmark 2800 Kgs. Lyngby (Denmark)

E-mail: ifan@fysik.dtu.dk ibchork@fysik.dtu.dk

Dr. D. Ravasio, Prof. Dr. J. Wendland

Carlsberg Laboratory

Gamle Carlsberg vej 4, 1799 København V (Denmark)

Dr. J. H. Montoya

SUNCAT Center for Catalysis and Interface Science

Department of Chemical Engineering, Stanford University

443 Via Ortega, Stanford, CA 94305 (USA)

Dr. S. Meier

Department of Chemistry, Technical University of Denmark 2800 Kongens Lyngby (Denmark)

\section{Prof. Dr. J. K. Nørskov}

SUNCAT Center for Catalysis and Interface Science

SLAC National Accelerator Laboratory

2675 Sand Hill Road, Menlo Park, CA 94025 (USA)

Prof. Dr. I. E. L. Stephens

Department of Mechanical Engineering

Massachusetts Institute of Technology (MIT)

77 Massachusetts Avenue, Cambridge, MA 02319 (USA)

(1) Supporting information and $\operatorname{ORCID(s)}$ from the author(s) for this

iD article are available on the WWW under http://dx.doi.org/10.1002/ anie. 201508851

Of (c) 2015 The Authors. Published by Wiley-VCH Verlag GmbH \& Co. $\mathrm{KGaA}$. This is an open access article under the terms of the Creative Commons Attribution Non-Commercial NoDerivs License, which permits use and distribution in any medium, provided the original work is properly cited, the use is non-commercial and no modifications or adaptations are made. 
has not been determined yet. In this work, we reveal the role of acetaldehyde as a likely reaction intermediate and product of $\mathrm{CO}$ reduction on $\mathrm{OD}-\mathrm{Cu}$ electrodes.

Oxide-derived $\mathrm{Cu}$ electrodes were produced following the procedure outlined by $\mathrm{Li}$ et al. (Supporting Information, section S.1). ${ }^{[14]}$ The resulting electrodes had a roughness factor of $87 \pm 10$ (section S.2). Electrochemical CO reduction was carried out in $\mathrm{CO}$-saturated $0.1 \mathrm{M} \mathrm{KOH}$ electrolyte. We used three approaches to analyze the reaction products. The gas phase composition over the electrolyte was measured by gas chromatography (GC). The liquid phase products were analyzed by extracting liquid samples and using a combination of nuclear magnetic resonance (NMR) spectroscopy and static headspace gas chromatography (HS-GC), the latter coupled with either a flame ionization detector (FID) or a mass spectrometer (MS). Figure 1 a shows the Faradaic
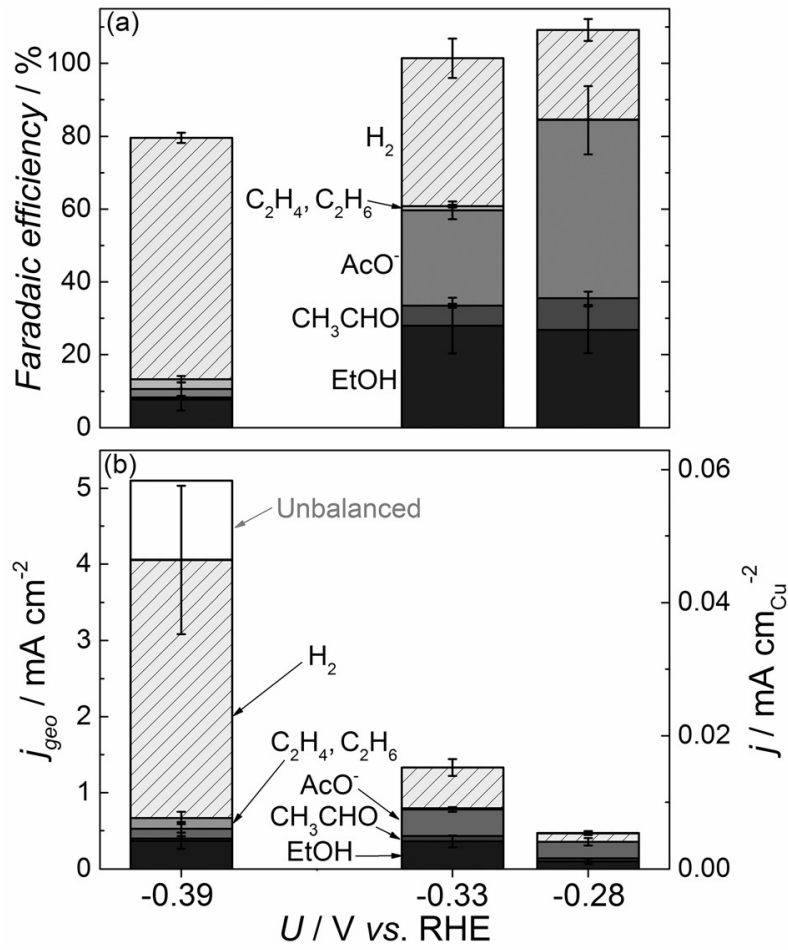

Figure 1. CO reduction on oxide-derived Cu electrodes. (a) Faradaic efficiency and (b) current density normalized to geometric and specific surface area for the individual products. Measurements were carried out in $\mathrm{CO}$ saturated (1.1 bar) $0.1 \mathrm{M} \mathrm{KOH}$. Note: The unbalanced contribution to the current is only added at $-0.39 \mathrm{~V}$, since the total Faradaic efficiency at the other two potentials are $\approx 100 \%$ within the experimental error. The data are based on at least three independent measurements for each potential. At $-0.28 \mathrm{~V}$, electrolysis was carried out until the accumulated charge reached $\approx 5 \mathrm{C}$, and at -0.33 and $-0.39 \mathrm{~V}$ until $\approx 10 \mathrm{C}$.

efficiency for $\mathrm{CO}$ reduction on oxide-derived $\mathrm{Cu}$ electrodes. Results resemble those reported by Kanan and co-workers. ${ }^{[14]}$ At $-0.33 \mathrm{~V}$ (vs. RHE; unless otherwise stated, all potentials in this work are given against the RHE scale), the current efficiency to ethanol and acetate is $25 \%$ for each, and $1 \%$ of the charge results in ethylene and ethane. Our observation that $\mathrm{C}_{2} \mathrm{H}_{4}$ and $\mathrm{C}_{2} \mathrm{H}_{6}$ is formed on OD-Cu is consistent with earlier works. ${ }^{[14,16]}$ The parasitic evolution of hydrogen accounts for the remaining $\approx 40 \%$. Interestingly, we observed that acetaldehyde, which is previously unreported on $\mathrm{OD}-\mathrm{Cu}$, is produced with a current efficiency of $5 \%$ at $-0.33 \mathrm{~V}$, or $\eta$ $\approx 400 \mathrm{mV}\left(\mathrm{U}_{\mathrm{CO} / \mathrm{CH} 3 \mathrm{CHO}}^{0}=0.10 \mathrm{~V}\right)$. The fact that we can only observe $\mathrm{C} 2$ products corresponds well with the previous observations that such products are favored on $\mathrm{Cu}$-based electrodes at low overpotentials under alkaline conditions. ${ }^{[14,17]}$ The total Faradaic efficiency at -0.28 and $-0.33 \mathrm{~V}$ comes, within the experimental error, to $\approx 100 \%$; we attribute the error to uncertainties in the calibration as well as minor leaks. At $-0.39 \mathrm{~V}, \approx 20 \%$ of the charge is not accounted for; this is likely to be caused by the high current density towards hydrogen evolution, where some of the $\mathrm{H}_{2}$ escapes the cell. Figure $1 \mathrm{~b}$ shows the partial current densities to the various products, normalized to the geometrical and specific electrode surface area. The overall current densities are two to three times higher than those reported by Li et al. at all potentials. ${ }^{[14]}$ This discrepancy could be caused by differences in mass transport, which is a function of the cell design. Alternatively, the greater capacitance observed for the electrodes produced in the current study could indicate that they have a higher surface area (section S.2).

Earlier studies on extended surfaces of $\mathrm{Cu}$ have suggested that acetylaldehyde is an intermediate for ethanol production from $\mathrm{CO}_{2}$ or $\mathrm{CO}$ reduction $;{ }^{[3,18]}$ Hori et al. reported that on polycrystalline $\mathrm{Cu}$, acetaldehyde is formed from $\mathrm{CO}$ at potentials negative of $-0.83 \mathrm{~V}$ RHE, albeit with a low selectivity of $0.5 \%$. They also showed that acetaldehyde can be reduced to ethanol, ${ }^{[16]}$ suggesting it is a soluble intermediate in the reaction (incidentally acetaldehyde is a key intermediate in ethanol oxidation, the reverse reaction ${ }^{[19]}$ ).

To investigate the possibility that acetaldehyde is an intermediate during $\mathrm{CO}$ reduction on $\mathrm{OD}-\mathrm{Cu}$, we tested its hydrogenation by introducing $10 \mathrm{~mm} \mathrm{CH}_{3} \mathrm{CHO}$ in Ar-saturated $0.1 \mathrm{M} \mathrm{KOH}$. As shown in Figure 2, ethanol is produced

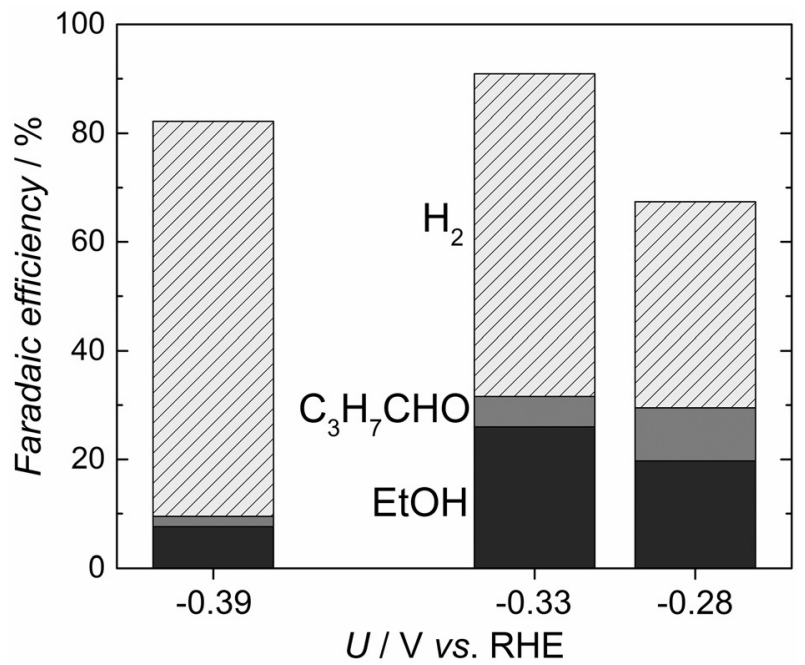

Figure 2. Faradaic efficiency for $\mathrm{CH}_{3} \mathrm{CHO}$ hydrogenation at different potentials. Measurements were carried out in Ar saturated (1.1 bar) $0.1 \mathrm{~m} \mathrm{KOH}$ with $10 \mathrm{~mm}$ of acetaldehyde. Note: The charge not accounted for is attributed to higher carbon oxygenates that have not been quantified. 
with a Faradaic efficiency of $\approx 30 \%$ at $-0.33 \mathrm{~V}$. Significant production of $\mathrm{C}_{3} \mathrm{H}_{7} \mathrm{CHO}$ also occurred. We did not observe this compound during our $\mathrm{CO}$ reduction experiments, possibly because of the lower acetaldehyde concentrations. However, we cannot discard the possibility that $\mathrm{C}_{3} \mathrm{H}_{7} \mathrm{CHO}$ is produced in concentrations below the detection limit from $\mathrm{CO}$ reduction. For lower added concentrations of acetaldehyde, much less ethanol and butanal were produced, possibly because of poorer mass transport of acetaldehyde to the electrode. This makes measurements at the concentrations observed for $\mathrm{CO}$ reduction $(\approx 120 \mu \mathrm{M})$ difficult. Interestingly, performing the same experiment with acetate did not yield any detectable $\mathrm{CO}$ reduction products; this suggests that acetate cannot be reduced further when it is formed at the

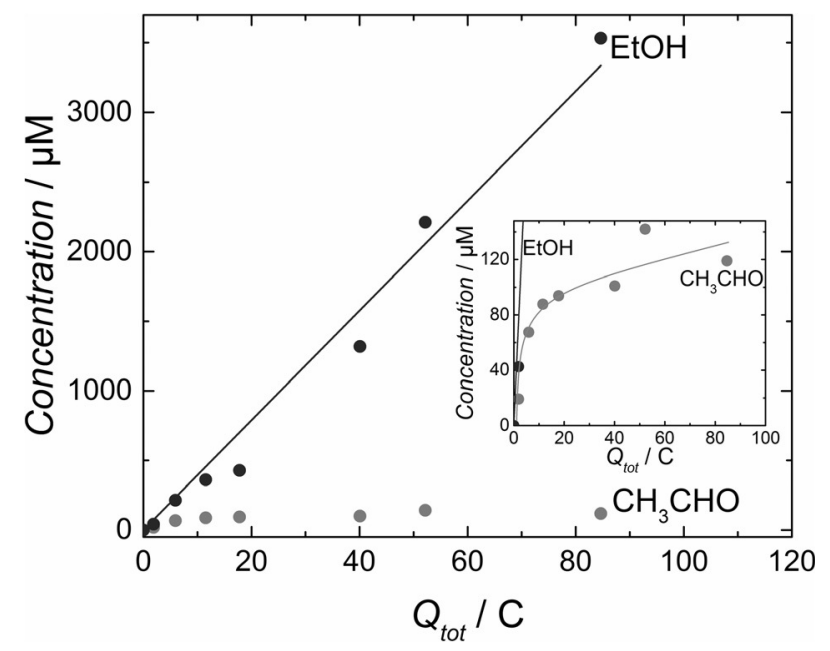

Figure 3. Acetaldehyde and ethanol concentration from $\mathrm{CO}$ reduction at $-0.33 \mathrm{~V}$ showed as a function of the charge involved in each measurement. Measurements were carried out in $0.1 \mathrm{M} \mathrm{KOH}$. electrode. Figure 3 shows the concentration of acetaldehyde and ethanol from $\mathrm{CO}$ reduction at $-0.33 \mathrm{~V}$ as a function of total electrolysis charge. Whereas ethanol concentration scales linearly with charge, the acetaldehyde concentration quickly saturates at $\approx 120 \mu \mathrm{M}$. We hypothesize that this is caused by the formation of aqueous acetaldehyde and its further reduction to ethanol reaching equilibrium.

In Figure 4, we provide the results of density functional theory (DFT) calculations of intermediates proceeding from adsorbed *OCCHO, a likely intermediate in the $\mathrm{C}-\mathrm{C}$ coupling pathway. ${ }^{[17,20]}$ The most favorable thermodynamic pathway towards ethanol on $\mathrm{Cu}(211)$, highlighted in black proceeds directly through this intermediate. Using other copper facets could alter the reactivity of the surface, but is unlikely to change the overall shape of the reaction pathway. ${ }^{[12]}$ Aqueous acetaldehyde can be seen as an intermediate, as previously reported. ${ }^{[21]}$ The step following the formation of $\mathrm{CH}_{3} \mathrm{CHO}$, a proton-coupled electron transfer producing adsorbed $* \mathrm{OCH}_{2} \mathrm{CH}_{3}$, is uphill at $0.0 \mathrm{~V}$ vs. RHE. However, it is downhill at $-0.3 \mathrm{~V}$, and will be even more exergonic with increasing concentrations of $\mathrm{CH}_{3} \mathrm{CHO}$. The lower free energy found for aqueous acetaldehyde compared to its adsorbed counterpart $(\approx 0.7 \mathrm{eV})$ yields a thermodynamic sink, supporting the experimental observation that it is released from the electrode and is present in the electrolyte in detectable concentrations.

Typically, NMR spectroscopy is used for detection of liquid products. ${ }^{[3,14,22]}$ Liquid state NMR spectroscopy requires analytes to be dissolved in a liquid phase for adequate detection. Alternative techniques can overcome this limitation. For instance, HS-GC heats up the liquid samples, in this case to $70^{\circ} \mathrm{C}$, and relies on the volatility of compounds for identification. ${ }^{[22]}$ This is particularly useful for products that evaporate readily, or that decompose into such compounds upon heating. Acetaldehyde has a boiling point of

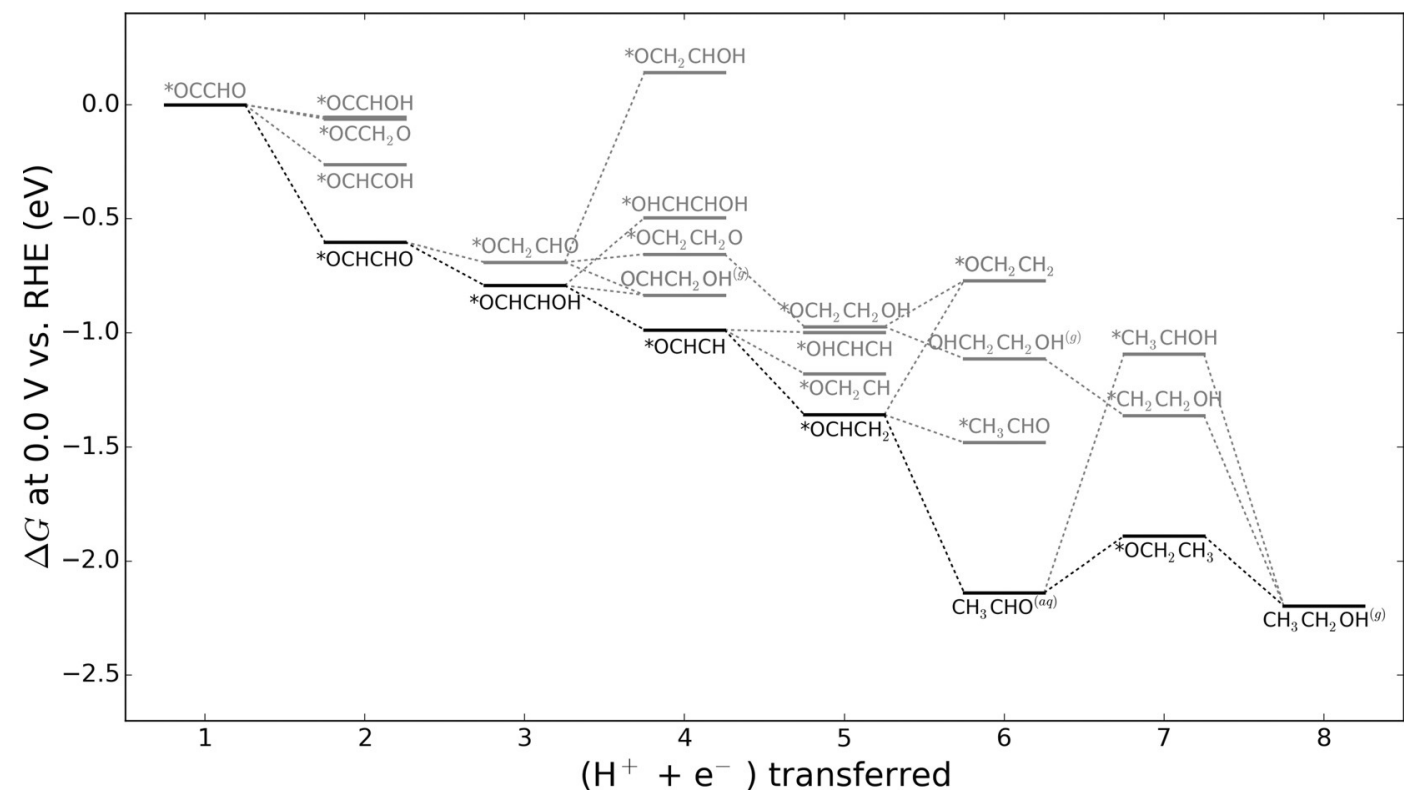

Figure 4. Free energy diagram for reduction of $\mathrm{C}-\mathrm{C}$ coupled intermediate $* \mathrm{OCCHO}$ on $\mathrm{Cu}(211)$. The free energy for $\mathrm{CH}_{3} \mathrm{CH}_{2} \mathrm{OH}{ }^{(\mathrm{g})}$ was calculated at $1 \mathrm{bar}$ and the free energy of $\mathrm{CH}_{3} \mathrm{CHO}^{(\mathrm{aq})}$ was calculated at a concentration of $100 \mu \mathrm{m}$. The steps marked with black represent the thermodynamically most favorable pathway. The gray represent other potential intermediates of higher energy. 

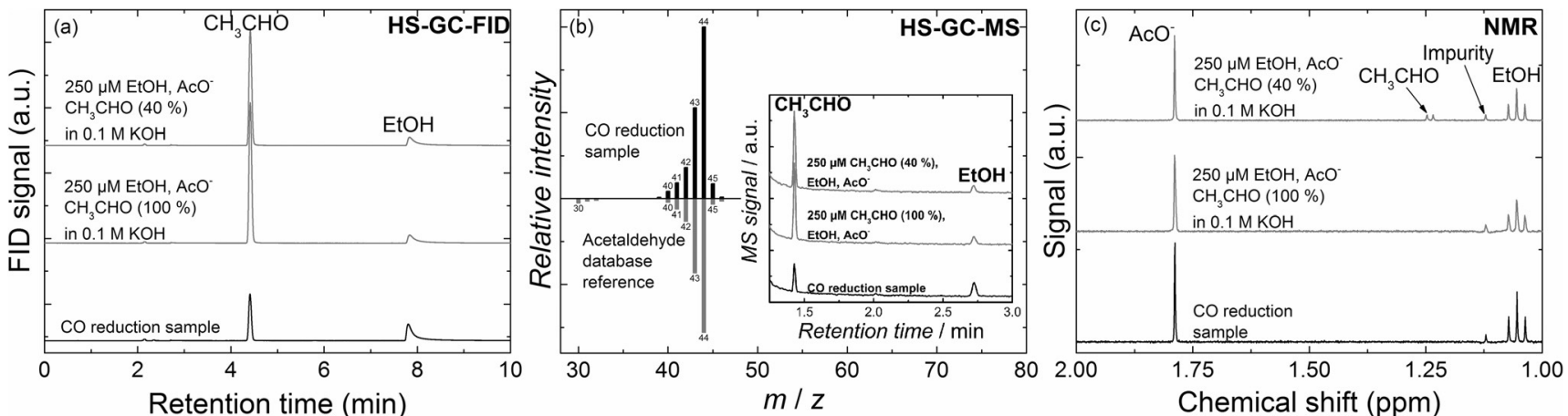

Figure 5. Liquid product analysis for a representative $\mathrm{CO}$ reduction sample from electrolysis at $-0.33 \mathrm{~V}$ (black) as well as two solutions containing $250 \mu \mathrm{M} \mathrm{CH}{ }_{3} \mathrm{CHO}, \mathrm{EtOH}$ and $\mathrm{AcO}^{-}$in $0.1 \mathrm{M} \mathrm{KOH}$ (gray), one made from a $40 \%$, and the other from a $100 \%$ acetaldehyde precursor. (a) $\mathrm{HS}-\mathrm{GC}$ FID chromatograms. (b) HS-GC-MS mass spectrum obtained from the acetaldehyde peak (at $\approx 1.5$ min) of a CO reduction measurement, compared to a database reference mass spectrum for acetaldehyde. Inset: HS-GC-MS chromatograms (c) NMR spectra.

$20.9^{\circ} \mathrm{C}$ under standard conditions. ${ }^{[23]}$ However, no trace of acetaldehyde was observed in the gas phase, which might be due to deviations from standard conditions and low concentrations. In Figure 5, a typical sample from $\mathrm{CO}$ reduction at $-0.33 \mathrm{~V}$ is compared with two different solutions containing the same liquid products as the sample, analyzed with HSGC-FID, HS-GC-MS, and NMR spectroscopy. For the two $\mathrm{GC}$ techniques, acetaldehyde can be clearly identified, both for the sample and the two prepared solutions. HS-GC-MS enables positive identification of acetaldehyde at mass 44. In contrast, acetaldehyde only appears in NMR through its diol form in the solution made from $40 \%$ acetaldehyde, observed as a doublet at $\approx 1.25 \mathrm{ppm}$. Neither the solution made from a $100 \%$ acetaldehyde precursor, nor the $\mathrm{CO}$ reduction sample shows any major signals that could be attributed to this compound, implying that routine NMR spectroscopy is not a reliable technique to identify acetaldehyde under basic conditions.

The organic chemistry of acetaldehyde, particularly in alkaline solutions, is complex. ${ }^{[2]}$ Acetaldehyde occurs in various hydrated, aggregated, and polymerized states in solution (see section S.3 for further discussion). We hypothesize that the main difficulty in detecting acetaldehyde with NMR spectroscopy is polymerization, possibly caused by a high local concentration at the electrode. This could yield insoluble compounds invisible to NMR and/or significant signal broadening. Three key observations support this hypothesis: a) For concentrated solutions in alkaline media, a yellow precipitate can be observed (Supporting Information, Figure S.6b), which could be attributed to an aggregated or polymerized form. b) Acetaldehyde standards aged in $0.1 \mathrm{M}$ $\mathrm{KOH}$ and extensive NMR signal accumulation in high-field NMR yield spectra consistent with the presence of acetaldehyde and its condensation products formed upon aging (Figure S.5). Since acetaldehyde occurs as a minor steadystate intermediate (Figure 3), the detection of acetaldehyde by more routine NMR methods, on the other hand, remains difficult. c) Upon acidification of the $0.1 \mathrm{~m} \mathrm{KOH}$ solution from $\mathrm{pH} 13$ to $\mathrm{pH} 1$, visible but broadened signals appear in the NMR spectra (Figure S.6a). We attribute their presence to ethyl acetate, an acetaldehyde dimer, which could result from an acid-catalyzed depolymerization process. Acetaldehyde chemistry is discussed further in section S.3, but is beyond the scope of this study.

The appearance of an additional product should, in principle, be observable through the Faradaic efficiency not reaching $100 \%$. However, the uncertainty in the analysis techniques could lead to minor products being overlooked.

In summary, we present evidence that acetaldehyde is a product and key intermediate in the electroreduction of carbon monoxide on oxide-derived copper. Detection of acetaldehyde in alkaline solutions using NMR spectroscopy is challenging, and thus, identification is performed using HSGC. Our results highlight the importance of using complementary methods for product detection from electrochemical reactions. Identification of acetaldehyde represents a first step in elucidating the $\mathrm{CO}$ reduction mechanism on $\mathrm{OD}-\mathrm{Cu}$ electrodes and paves the way for the design of improved catalysts.

\section{Experimental Section}

Rectangular electrodes of $5 \times 10 \mathrm{~mm}$ were cut and electropolished. They were annealed in air at $500^{\circ} \mathrm{C}$ for an hour and cooled to room temperature, before being mounted in the electrochemical cell where the $\mathrm{Cu}_{2} \mathrm{O}$ surface layer was reduced chronopotentiometrically at $7 \mathrm{~mA} \mathrm{~cm}^{-2}$. Electrode capacitance measured by cyclic voltammetry was used to determine the roughness of the electrodes.

The working electrode (WE) and counter electrode (CE) compartments were separated by a Nafion 117 membrane and the $\mathrm{WE}$ and reference electrode (RE) compartments were separated by an ion-conducting ceramic frit. A gold mesh was used as $\mathrm{CE}$, while an $\mathrm{Hg} / \mathrm{HgSO}_{4}$ electrode was used as reference, calibrated to the reversible hydrogen electrode (RHE) in the same electrolyte. CO reduction was carried out potentiostatically at the desired potential. $85 \%$ of the uncompensated ohmic drop was corrected for in the software, as measured through electrochemical impedance spectroscopy ${ }^{[25]}$ If significant, the remaining $15 \%$ was corrected for after the experiment. The ohmic drop typically ranged from 20 to $50 \Omega$, depending on the WE position relative to the RE.

During measurements, $\mathrm{CO}$ reduction products accumulate in the electrolyte and headspace of the WE compartment. The gaseous product composition was analyzed by a GC mounted with a flame ionization detector (FID) and a thermal conductivity detector (TCD). 
Liquid products were analyzed through HS-GC and NMR spectroscopy.

DFT calculations were performed on a $4 \times 3 \times 3$-atom periodic computational cell corresponding to the (211) facet of fcc $\mathrm{Cu}$, with a 4-atom long step edge. The (211) facet was chosen based on the presence of step edge, four-fold, and three-fold terrace sites that may occur on $\mathrm{OD}-\mathrm{Cu}$. Electronic energies were determined with the Dacapo DFT calculator as implemented in the open-source Atomic Simulation Environment (ASE) ${ }^{[26]}$ and the revised Perdew-BurkeErnzerhof (RPBE) exchange correlation functional was chosen for its relative accuracy in describing chemisorption energies. ${ }^{[27]}$ The geometries of multiple configurations of each adsorbate corresponding to placement on each available binding site were optimized into local energy minima, and the most stable configuration selected for the energies presented with a free energy correction corresponding to vibrational contributions determined in the harmonic approximation. Static solvation corrections based on the presence of aldehyde and hydroxyl groups on adsorbates similar to previous work ${ }^{[12,28]}$ are also included.

More details can be found in the Supporting Information.

\section{Acknowledgements}

We acknowledge funding from Danish Council for Strategic Research's NACORR project. I.E.L. Stephens is the recipient of the Peabody Visiting Associate Professorship from the Department of Mechanical Engineering at MIT. We also acknowledge the assistance of Casper Hoeck and Charlotte H. Gotfredsen in setting up and carrying out NMR spectroscopy measurements, as well as Zarko Jovanov and Ana Sofia Varela in setting up the HS-GC equipment.

Keywords: analytical chemistry - catalysis - electrochemistry · energy conversion $\cdot$ materials science

How to cite: Angew. Chem. Int. Ed. 2016, 55, 1450-1454 Angew. Chem. 2016, 128, 1472-1476

[1] A. Goeppert, M. Czaun, J. P. Jones, G. K. Surya Prakash, G. A Olah, Chem. Soc. Rev. 2014, 43, $7995-8048$.

[2] Y. Hori, in Mod. Asp. Electrochem. (Eds.: C. G. Vayenas, R. E. White, M. E. Gamboa-Aldeco), Springer, Berlin, 2008, pp. $89-$ 189.

[3] K. P. Kuhl, E. R. Cave, D. N. Abram, T. F. Jaramillo, Energy Environ. Sci. 2012, 5, 7050-7059.

[4] K. J. P. Schouten, Y. Kwon, C. J. M. van der Ham, Z. Qin, M. T. M. Koper, Chem. Sci. 2011, 2, 1902-1909.

[5] A. Wuttig, Y. Surendranath, ACS Catal. 2015, 5, 4479-4484.
[6] W. Tang, A. A. Peterson, A. S. Varela, Z. P. Jovanov, L. Bech, W. J. Durand, S. Dahl, J. K. Nørskov, I. Chorkendorff, Phys. Chem. Chem. Phys. 2012, 14, 76-81.

[7] Y. Chen, C. W. Li, M. W. Kanan, J. Am. Chem. Soc. 2012, 134, 19969-19972.

[8] J. Medina-Ramos, J. L. Dimeglio, J. Rosenthal, J. Am. Chem. Soc. 2014, 136, $8361-8367$.

[9] W. Zhu, Y. J. Zhang, H. Zhang, H. Lv, Q. Li, R. Michalsky, A. A. Peterson, S. Sun, J. Am. Chem. Soc. 2014, 136, 16132-16135.

[10] M. Asadi, B. Kumar, A. Behranginia, B. A. Rosen, A. Baskin, N. Repnin, D. Pisasale, P. Phillips, W. Zhu, R. Haasch, et al., Nat. Commun. 2014, 5, 4470.

[11] A. S. Varela, N. R. Sahraie, J. Steinberg, W. Ju, H. S. Oh, P. Strasser, Angew. Chem. Int. Ed. 2015, 54, 10758-10762; Angew. Chem. 2015, 127, 10908-10912.

[12] A. A. Peterson, J. K. Nørskov, J. Phys. Chem. Lett. 2012, 3, $251-$ 258.

[13] C. W. Li, M. W. Kanan, J. Am. Chem. Soc. 2012, 134, 7231-7234.

[14] C. W. Li, J. Ciston, M. W. Kanan, Nature 2014, 508, 504-507.

[15] A. Verdaguer-Casadevall, C. W. Li, T. P. Johansson, S. B. Scott, J. T. McKeown, M. Kumar, I. E. L. Stephens, M. W. Kanan, I. Chorkendorff, J. Am. Chem. Soc. 2015, 137, 9808-9811.

[16] Y. Hori, R. Takahashi, Y. Yoshinami, A. Murata, J. Phys. Chem. B 1997, 101, 7075-7081.

[17] J. H. Montoya, C. Shi, K. Chan, J. K. Nørskov, J. Phys. Chem. Lett. 2015, 6, 2032-2037.

[18] Y. Hori, I. Takahashi, O. Koga, N. Hoshi, J. Phys. Chem. B 2002, $106,15-17$

[19] M. Heinen, Z. Jusys, Y. X. Chen, R. J. Behm, J. Phys. Chem. C 2010, 114, 9850-9864.

[20] J. K. Nørskov, A. A. Peterson, J. H. Montoya, ChemCatChem 2013, $5,737-742$

[21] F. Calle-Vallejo, M. T. M. Koper, Angew. Chem. Int. Ed. 2013, 52, 7282-7285; Angew. Chem. 2013, 125, 7423-7426.

[22] J. Hong, W. Zhang, J. Ren, R. Xu, Anal. Methods 2013, 5, 10861097.

[23] R. D. Harrison, Revised Nuffield Advanced Science Book of Data, Longman, Harlow, 1984

[24] Y. Kwon, S. C. S. Lai, P. Rodriguez, M. T. M. Koper, J. Am. Chem. Soc. 2011, 133, 6914-6917.

[25] V. Čolić, A. S. Bandarenka, J. Tymoczko, A. Maljusch, A. Ganassin, W. Schuhmann, ChemElectroChem 2015, 2, 143-149.

[26] S. R. Bahn, K. W. Jacobsen, Comput. Sci. Eng. 2002, 4, 56-66.

[27] B. Hammer, L. Hansen, J. Nørskov, Phys. Rev. B 1999, 59, $7413-$ 7421.

[28] A. A. Peterson, F. Abild-Pedersen, F. Studt, J. Rossmeisl, J. K. Nørskov, Energy Environ. Sci. 2010, 3, 1311-1315.

Received: September 21, 2015

Revised: October 22, 2015

Published online: December 21, 2015 